\title{
Colgajo perforante en hélice basado en arteria peronea para reconstrucción distal de extremidad inferior*
}

\author{
Drs. GÜNTHER MANGELSDORFF G. ${ }^{1}$, JOSÉ RAMÓN RODRÍGUEZ A. ${ }^{1}$, \\ MARÍA FERNANDA DEICHLER V. ${ }^{1}$, CAMILA HEVIA S. ${ }^{1}$, \\ ANDREA HASBÚN N. ${ }^{1}$, RICARDO ROA G. ${ }^{1}$ \\ 1 Servicio de Cirugía Plástica y Quemados, Hospital del Trabajador. \\ Santiago, Chile.
}

\begin{abstract}
Peroneal artery propeller perforator flap for distal lower limb reconstruction

Introduction: Propeller flaps are local pedicle flaps, based on a perforator vessel, which acts as the pivot point for the skin island that can be rotated up to $180^{\circ}$. These flaps can be performed wherever a perforator vessel of adequate size is encountered, expanding the reconstructive options for lower limb defects. Clinical case: We present a case of reconstruction of soft-tissue defect of the leg using a peroneal artery propeller perforator flap. A review of the main advantages of this technique for reconstruction of lower limb defects is also presented.
\end{abstract}

Key words: Propeller flaps, lower limb, defects.

\section{Resumen}

Introducción: El colgajo en hélice (propeller flap) corresponde a un tipo de colgajo local pediculado, basado en vasos perforantes, que actúan como punto pivote sobre el cual se rota la isla cutánea hasta en $180^{\circ}$. Este tipo de colgajo puede ser efectuado en cualquier sitio donde exista un vaso perforante de calibre adecuado, ampliando las alternativas de cobertura para defectos de extremidad inferior. Caso clínico: Presentamos un caso de cobertura de defecto de partes blandas secundario a aplastamiento de tobillo, utilizando un colgajo en hélice basado en perforante de arteria peronea. Se discuten las principales consideraciones respecto al uso de esta técnica en reconstrucción de extremidad inferior.

Palabras clave: Colgajo en hélice, extremidades inferiores, defectos.

*Recibido el 29 de enero de 2013 y aceptado para publicación el 2 de marzo de 2013.

Los autores no refieren conflictos de interés.

Correspondencia: Dr. Günther Mangelsdorff G.

Ramón Carnicer 185, Santiago, Chile.

gmangels@gmail.com 


\section{Introducción}

Los defectos de cobertura de la pierna constituyen un desafío constante en cirugía reconstructiva, especialmente cuando existe exposición ósea, tendínea, articular o de materiales de osteosíntesis ${ }^{1}$. La introducción de colgajos basados en perforantes ha determinado una revolución en el campo de la cirugía reconstructiva, ofreciendo nuevas alternativas de cobertura para defectos de la extremidad inferior, ya sea como colgajos libres o pediculados ${ }^{2-8}$. Dentro de las ventajas de los colgajos basados en perforantes se incluye la preservación de la estructura y función muscular, mayor versatilidad del diseño y movilización, vascularización confiable y menor morbilidad de zonas dadoras ${ }^{4}$. Los avances en el conocimiento de la anatomía vascular, ${ }^{9}$, en conjunto con el método de disección de colgajos "estilo libre"1", han permitido el desarrollo de los colgajos en hélice (propeller flap). Este tipo de colgajo corresponde a un colgajo local pediculado, basado en vasos perforantes, que actúan como punto pivote sobre el cual se rota la isla de piel, permitiendo una rotación de hasta $180^{\circ 12}$.

Presentamos un caso de cobertura cutánea de tobillo secundaria a necrosis por aplastamiento, mediante un colgajo perforante en hélice basado en arteria peronea. Se discuten las principales indicaciones y consideraciones respecto al uso de esta técnica en reconstrucción de extremidad inferior.

\section{Caso clínico}

Hombre de 35 años; con antecedente de hipertensión y tabaquismo. Fue atropellado por microbus, con aplastamiento de pie izquierdo, sin lesiones óseas. Presentó dos escaras en cara lateral de tobillo y pie izquierdo, luego de escarectomía inicial se establecieron dos defectos de cobertura, en un área total de $4,5 \times 10 \mathrm{~cm}$ en la cara lateral del tobillo y talón izquierdo. (Figura 1).

Se decidió efectuar cobertura del defecto con colgajo en hélice, basado en perforante de arteria peronea, para otorgar cobertura estable al roce y movilidad del segmento comprometido, con un adecuado contorno para el uso de calzado. Se realizó marcación preoperatoria de perforantes adyacentes al defecto con Doppler portátil, y mediante una incisión exploratoria se identificó la perforante previamente mapeada. Tomando la ubicación del pedículo vascular como eje de rotación se marcó la isla de piel con un segmento largo proximal, cuya longitud se obtuvo de la medición desde el punto de pivote al extremo distal del defecto (agregando $2 \mathrm{~cm}$ de seguridad por la contracción primaria del colgajo), y un segmento corto distal desde el pedículo al borde proximal del defecto. El tamaño final del colgajo fue de $21 \times 5 \mathrm{~cm}$, con el vaso perforante ubicado en la unión del tercio distal con el tercio medio del mismo (Figura 1).

Mediante disección subfascial se completó la

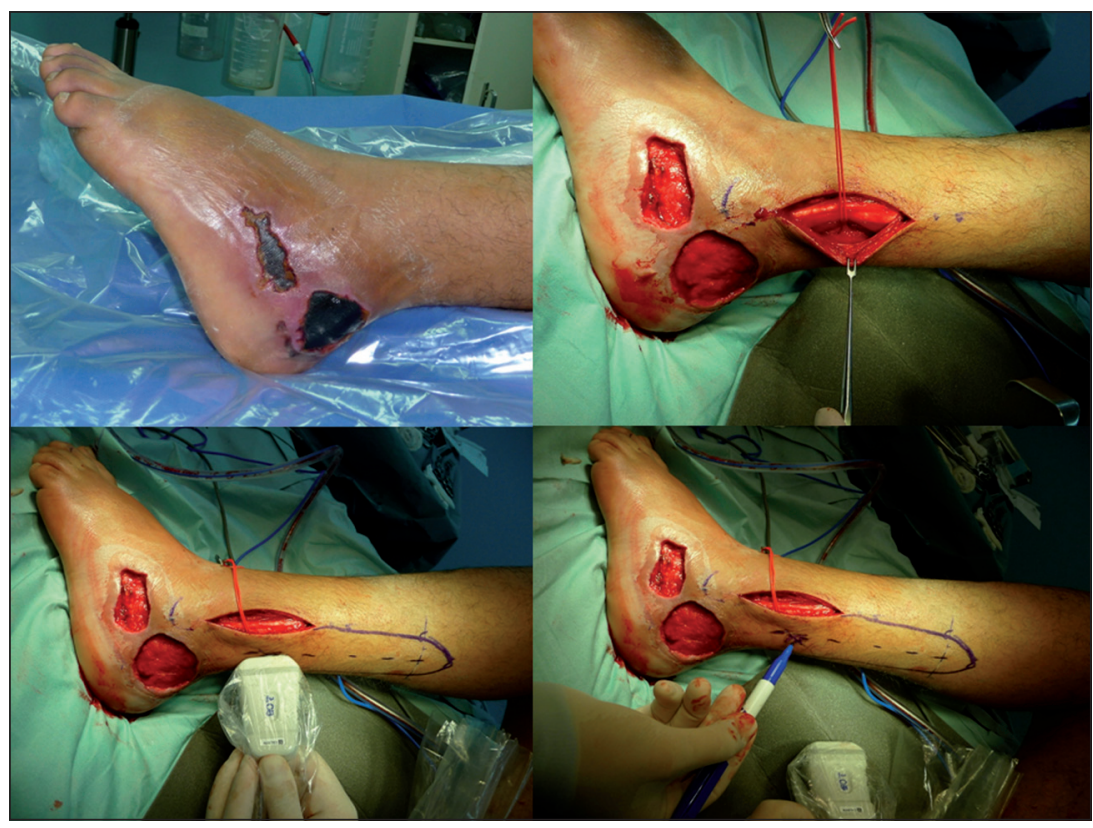

Figura 1. Vista preoperatoria del defecto de partes blandas. Vaso perforante identificado mediante incisión exploratoria. Diseño del colgajo. 
elevación del colgajo y se realizó esqueletización de los vasos perforantes septocutáneos, obteniendo un pedículo de $3 \mathrm{~cm}$ de longitud (Figuras 1 y 2). Luego de comprobar la adecuada perfusión del colgajo, se realizó rotación de éste en $180^{\circ}$ contrareloj en torno a su pedículo (movimiento similar a la rotación de una hélice), obteniendo cobertura completa de la zona de exposición ósea con la rama más larga del colgajo y cobertura parcial de la zona dadora con la rama más corta del mismo (Figura 3). Se efectuó cierre primario del defecto residual en la zona. El tiempo operatorio fue de 120 min. Luego de una revisión marginal del borde distal del colgajo por congestión venosa, se logró cobertura completa y estable, con un resultado de contorno satisfactorio que permitió un buen ajuste de zapato común y reintegro laboral del paciente (Figura 4).

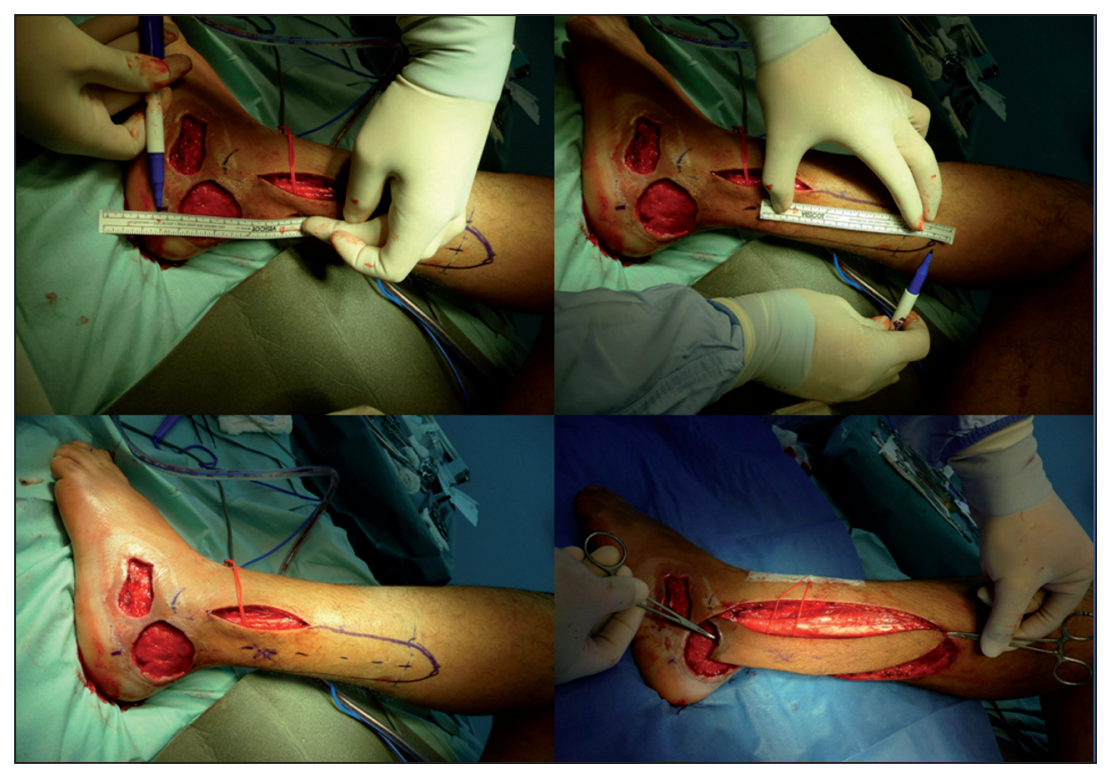

Figura 2. Diseño del colgajo en hélice con eje excéntrico en relación al defecto.

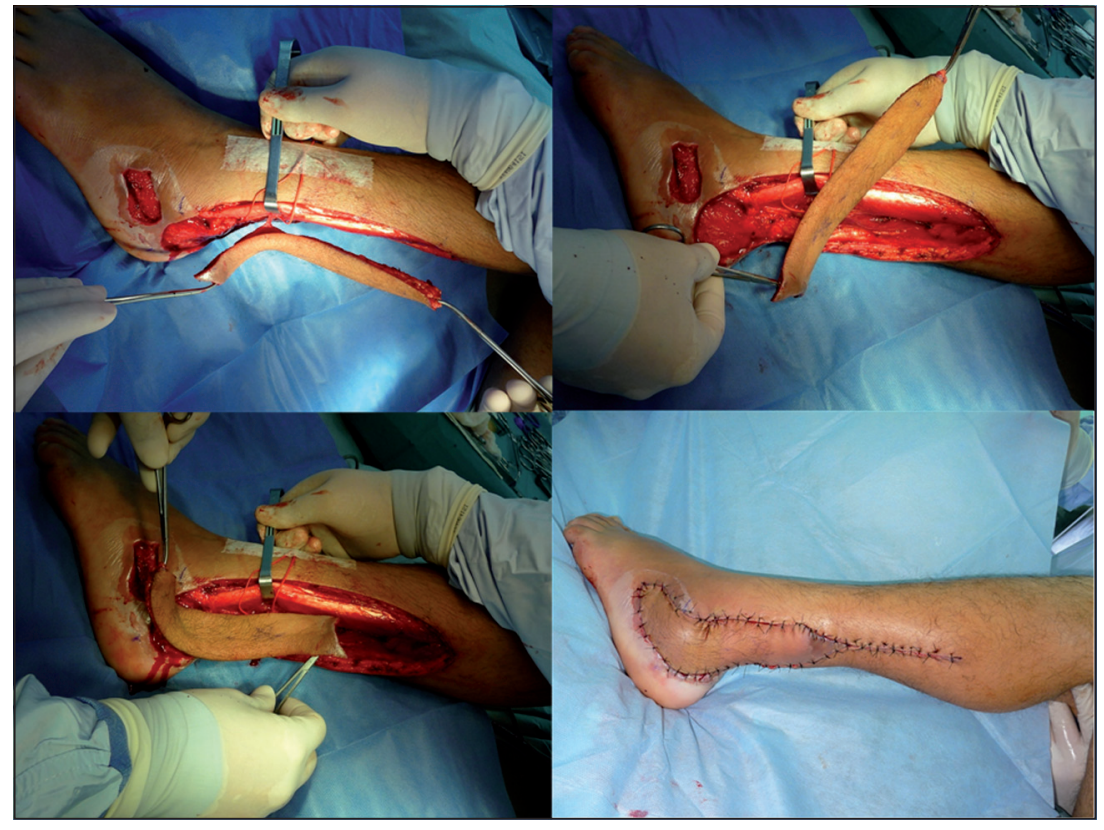

Figura 3. Elevación del colgajo y exposición del pedículo vascular. Cierre del defecto. Resultado postoperatorio inmediato. 


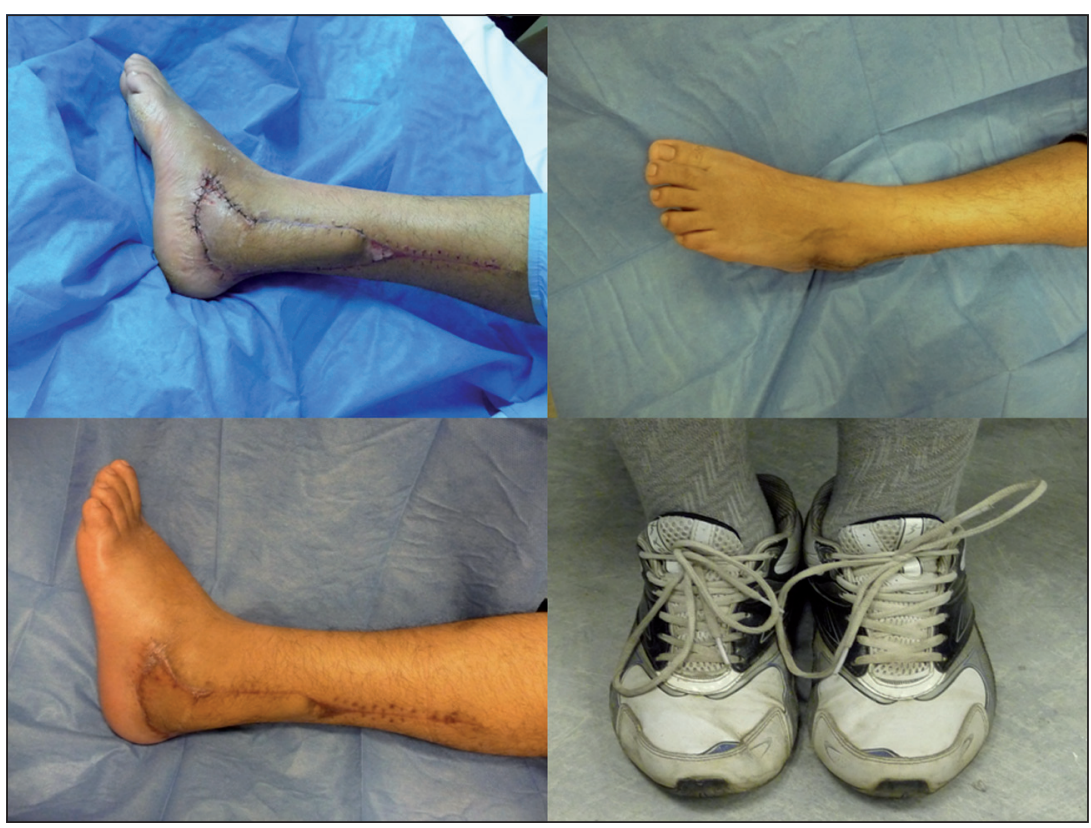

Figura 4. Vista postoperatoria tardía.

\section{Discusión}

Durante los últimos años, los colgajos basados en perforantes, se han convertido en una herramienta fundamental para la reconstrucción de defectos de partes blandas de la extremidad inferior. La amplia distribución de vasos perforantes confiere una gran versatilidad de diseño, otorgando un mejor rango de movilidad y una mayor cantidad de tejido respecto a los colgajos clásicos ${ }^{2-8}$. La visualización directa del pedículo vascular permite obtener una vascularización confiable y entrega la oportunidad de elegir los vasos con mejores características, en cuanto a posición y calibre, aumentando las posibilidades de conseguir una reconstrucción exitosa ${ }^{2}$. Por otra parte, los colgajos perforantes pediculados pueden confeccionarse en la vecindad del defecto, utilizando tejidos semejantes a la zona dañada. Al igual que para los colgajos libres, se preserva la musculatura y generalmente es posible efectuar cierre primario de la zona dadora, con mejores resultados estéticos ya que eventualmente no se requeriría usar injertos dermoepidérmicos en esas zonas ${ }^{4}$.

El colgajo en hélice o propeller flap fue descrito por Hyakusoku en $1991^{13}$, como una alternativa para la corrección de cicatrices retráctiles en codo y axila. $\mathrm{Su}$ diseño se basaba en un pedículo subcutáneo con una isla cutánea que consistía en dos porciones (las hélices), las cuales se rotaban en $90^{\circ}$ logrando así la liberación de la zona dañada. Posteriormente, Hallock propuso realizar la esqueletización de la per- forante, obteniendo así una rotación en 180 grados, con la ventaja comparativa de lograr cubrir tanto el defecto como la zona dadora ${ }^{14}$.

La clasificación actual de estos colgajos se establece según el consenso de Tokyo ${ }^{12}$, que define tres categorías: 1) Colgajo en hélice con pedículo subcutáneo: el pedículo es aleatorio, no se esqueletiza y la rotación de la isla de piel es de hasta $\left.90^{\circ} ; 2\right)$ Colgajo en hélice con pedículo basado en perforante: el pedículo se basa en vasos perforantes, los cuales se esqueletizan logrando así una rotación de hasta $180^{\circ}$; 3) Colgajo en hélice supercargado: posee una perforante esqueletizada con rotación de la isla de piel hasta en $180^{\circ}$ y tiene además una arteria y vena adicionales en el otro extremo del colgajo, que luego son anastomosadas a vasos del lecho receptor una vez determinada la posición final del colgajo. Este puede ser el diseño original del colgajo, así como también puede ser utilizado como una medida de rescate frente a un colgajo con congestión venosa o isquemia.

Existen numerosas publicaciones respecto a colgajos en hélice basados en perforantes para reconstrucción de extremidad inferior, ilustrando sus distintos usos y modificaciones, con o sin esqueletización del vaso perforante y con diferentes grados de rotación ${ }^{2-7}$. Para planificar la reconstrucción de extremidad inferior se deben considerar una serie de elementos incluyendo el tamaño del defecto y las estructuras expuestas, la condición vascular del tejido vecino, la anatomía vascular de la extremidad y el largo del pedículo vascular requerido ${ }^{4}$. 
Los colgajos en hélice constituyen la alternativa de elección para cobertura de defectos de tamaño pequeño o mediano en la pierna, si las condiciones vasculares del tejido vecino son adecuadas ${ }^{4}$. El colgajo en hélice, basado en perforante de arteria peronea, está indicado para cobertura de defectos en la región lateral pierna distal, tobillo y talón (rotación $180^{\circ}$ ). Variando su diseño inicial o su ángulo de rotación puede ser útil en cobertura de defectos de cara anterior y posterior del tobillo y parte proximal del dorso de pie. Este colgajo puede rotarse hasta en $180^{\circ}$ y es factible obtener una isla de piel de gran tamaño a partir de un único vaso perforante, debido a que los vasos perforantes de la arteria peronea poseen un calibre adecuado y existen múltiples comunicaciones axiales entre ellos ${ }^{1,5}$. El tiempo operatorio es menor respecto a un procedimiento microquirúrgico, ya que no se requiere de anastomosis y la intervención puede realizarse bajo anestesia locorregional. La identificación preoperatoria de perforantes por Doppler portátil es útil, pero no sería mandatoria dada la localización superficial de los vasos principales, lo cual puede generar falsas señales positivas o negativas ${ }^{1}$. El estudio complementario puede contemplar además el uso de Doppler color, angiografía por tomografía computada y angiografía por resonancia magnética. Se ha sugerido que la angiografía por tomografía computada sería superior a otros métodos de imágenes, particularmente para extremidades, permitiendo una planificación más adecuada para el diseño de colgajos en hélice ${ }^{15}$. Debemos destacar que la exploración quirúrgica determina en forma precisa la ubicación de la perforante; por lo que el diseño y elevación del colgajo deben efectuarse sólo después de esta disección inicial exploratoria.

La insuficiencia venosa de la punta o del colgajo completo, constituye la complicación más frecuente. Se debe a una selección inadecuada de perforantes o debido a disección insuficiente alrededor del pedículo, especialmente alrededor de la vena ${ }^{1}$. Usualmente se observa una coloración violácea en colgajos perforantes, lo cual suele corresponder a congestión transitoria que se resuelve con la estabilización del flujo. Si la insuficiencia se limita a un segmento apical del colgajo, la mayoría regresa en forma espontánea. En caso de insuficiencia severa puede ser necesario realizar una supercarga venosa, mediante anastomosis microquirúrgica o, en último caso, desrrotar el colgajo a su posición original. Una forma de prevenir la insuficiencia venosa es disecar el pedículo vascular lo máximo posible hasta el vaso de origen ${ }^{3}$.

En la actualidad los colgajos en hélice basados en perforantes, poseen un rol clave en la reconstrucción de defectos de cobertura de extremidad inferior. El caso descrito ilustra las ventajas de esta técnica, proporcionando un adecuado resultado de forma y función.

\section{Referencias}

1.- Georgescu AV. Propeller perforator flaps in distal lower leg: evolution and clinical applications. Arch Plast Surg. 2012;39:94-105.

2.- Pignatti M, Pasqualini M, Governa M, Bruti M, Rigotti G. Propeller flaps for leg reconstruction. J Plast Reconstr Aesthet Surg. 2008;61:777-83.

3.- D’Arpa S, Córdova A, Pignatti M, Moschella F. Freestyle pedicled perforator flaps: safety, prevention of complications, and management based on 85 consecutive cases. Plast Reconstr Surg. 2011;128:892-906.

4.- Masia J, Moscatiello F, Pons G, Fernández M, López S, Serret P. Our experience in lower limb reconstruction with perforator flaps. Ann Plast Surg. 2007;58:507-12.

5.- Schaverien MV, Hamilton SA, Fairburn N, Rao P, Quaba AA. Lower limb reconstruction using the islanded posterior tibial artery perforator flap. Plast Reconstr Surg. 2010;125:1735-43.

6.- Lecours C, Saint-Cyr M, Wong C, Bernier C, Mailhot E, Tardif M, et al. Freestyle pedicle perforator flaps: clinical results and vascular anatomy. Plast Reconstr Surg. 2010;126:1589-603.

7.- Teo TC. Perforator local flaps in lower limb reconstruction. Cir Plast Iberlatinamer. 2006;32:15-6.

8.- Jakubietz RG, Jakubietz MG, Gruenert JG, Kloss DF. The 180-degree perforator-based propeller flap for soft tissue coverage of the distal, lower extremity: a new method to achieve reliable coverage of the distal lower extremity with a local, fasciocutaneous perforator flap. Ann Plast Surg. 2007;59:667-71.

9.- Taylor GI. The angiosomes of the body and their supply to perforator flaps. Clin Plast Surg. 2003;30:331-42.

10.- Saint-Cyr M, Wong C, Schaverien M, Mojallal A, Rohrich RJ. The perforasome theory: vascular anatomy and clinical implications. Plast Reconstr Surg. 2009; 124:1529-44.

11.- Asko-Seljavaara S. Free style free flaps. Congress of the International Society of Reconstructive Microsurgery. 1983 Jun 19-30; New York, NY.

12.- Pignatti M, Ogawa R, Hallock GG, Mateev M, Georgescu AV, Balakrishnan G, et al. The "Tokyo" consensus on propeller flaps. Plast Reconstr Surg. 2011;127:716-22.

13.- Hyakusoku H, Yamamoto T, Fumiiri M. The propeller flap method. Br J Plast Surg. 1991;44:53-4.

14.- Hallock GG. The propeller flap version of the adductor muscle perforator flap for coverage of ischial or trochanteric pressure sores. Ann Plast Surg. 2006;56:540-2.

15.- Ono S, Chung KC, Hayashi H, Ogawa R, Takami Y, Hyakusoku H. Application of multidetector-row computed tomography in propeller flap planning. Plast Reconstr Surg. 2011;127:703-11. 